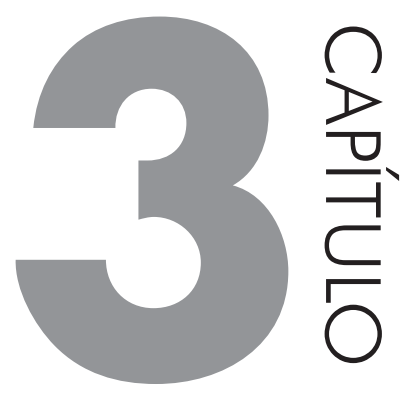

\title{
A EDUCAÇÃO ABERTA COM CIÊNCIA ABERTA E ESCOLARIZAÇÃO ABERTA PARA PESQUISA E INOVAÇÃO RESPONSÁVEIS
}

\section{ALEXANDRA OKADA, ELOY RODRIGUES}

\section{INTRODUÇÃO}

Este artigo visa introduzir o conceito criado pela Comissão Europeia - EC "Pesquisa e Inovação Responsáveis" - traduzido do termo em inglês "Responsible Research and Innovation" cujo acrônimo é RRI (EC, 2015). E também visa refletir sobre a inter-relação com a Educação aberta "open education", ciência aberta "open science" e a escolarização aberta "open schooling" para abrir discussões relevantes sobre a formação de educadores e profissionais do futuro.

O mundo atual globalizado e em rede (Castells \& Cardoso, 2005) apresentam transformações cada vez mais rápidas decorrentes das contínuas inovações científicas e tecnológicas e dos inúmeros "desafios globais", por exemplo, meio ambiente, energia, saúde, alimento, recursos e segurança. A fundação Global Challenges destaca doze riscos relacionados com os desafios globais que ameaçam a humanidade, dentre eles, extrema mudança climática, catástrofes ecológicas, guerra nuclear e doenças epidêmicas (ebola, HIV) (Pamlin \& Armstrong, 2015). Este cenário de contrastes drásticos do século XXI exige novas abordagens para que a ciência "com" e "para" a sociedade juntas possam desenvolver um futuro sustentável. Com este propósito, a abordagem RRI tem sido destacada para promover maior parceria 
entre os distintos representantes sociais com o propósito de possibilitar maior interação no planejamento, desenvolvimento e resultados das inovações científicas para atender as necessidades e expectativas prioritárias do presente e futuro.

Um dos problemas atuais mais sérios centra-se na escassez de recursos. Uma parte substancial do programa de pesquisa da Comissão Europeia Horizon 2020 um dos maiores do mundo - visa encontrar respostas para problemas como fornecimento de energia, o aquecimento global, a saúde pública, a segurança ou os recursos hídricos e alimentares, face ao rápido crescimento populacional, com estimativas de nove bilhões de habitantes em 2050. O investimento na investigação científica e tecnológica prioriza salvaguardar a eficiência e a diversidade dos recursos para proteger o ambiente e lutar contra a pobreza e a exclusão social para criar uma sociedade melhor para os cidadãos. (Comissão Europeia, 2014).

A educação contemporânea ocupa um papel central para a formação de estudantes, professores, profissionais e pesquisadores com práticas cada vez mais abertas, inclusivas e colaborativas que sejam apoiadas em princípios, metodologias e tecnologias acessíveis e transparentes. A parceria, interação e colaboração entre diversos atores da sociedade são elementos-chave para educação aberta, ciência aberta e RRI principalmente por promover a coaprendizagem, coinvestigação e novas coautorias visando a co-construção de conhecimentos "para" e "com" a sociedade em busca de viabilidade e sustentabilidade (Okada, 2014).

\section{O PROPÓSITO DA ABERTURA}

Devido ao alcance amplo das novas tecnologias, as pessoas têm um acesso extremamente maior à informação e à interação. O conceito de "Abertura" do inglês "Openness" tornou-se um propósito cada vez mais popular principalmente com a cultura digital. No entanto, este conceito não está apenas associado com o movimento de software livre ou conteúdo aberto. A noção de abertura emergiu muito antes da era digital para destacar uma filosofia inovadora e o fenômeno emergente que vem se ampliando cada vez mais através de várias iniciativas tais como: ciência aberta, universidades abertas, software aberto, produto aberto, conteúdo aberto, repositórios abertos, recursos educacionais abertos, educação aberta, comunidades abertas, aprendizagem aberta, código de programação aberto e democracia aberta (Okada, 2007; Rodrigues, 2015).

O termo "ciência aberta" emergiu no final do século XVI e início Século XVII, e foi vital para a revolução científica. A disseminação ampla do conhecimento tornou-se possível com a tecnologia, desde Gutenberg com a revolução da impressão em 1439. E somente após cinco séculos, a circulação e co-construção do conhecimento tornaram-se muito mais abrangentes e rápidas com a revolução digital em 1950. O objetivo da ciência aberta é o conhecimento como "bem de 
acesso aberto" ao público, diferente da ciência comercial que visa lucrar com direitos do conhecimento como propriedade privada. No entanto, a "ciência aberta" e a "ciência comercial" orientada para pesquisa e desenvolvimento, com base em informações proprietárias, formam um par complementar de subsistemas institucionalmente distintos. Um dos grandes desafios para a política pública tem sido manter estes dois subsistemas em equilíbrio produtivo adequado, para que as capacidades especiais de cada um possam amplificar a produtividade do outro (David, 2007). Entretanto, o acesso digital aberto à literatura científica, tal como hoje o conhecemos, é um fenómeno com apenas duas décadas. O primeiro periódico científico (journal em inglês) com acesso aberto para o público foi o Journal of Medical Internet Research em 1998. A definição de ciência aberta ampliou-se muito mais transformando-se num movimento para tornar a pesquisa científica tanto os resultados como processo (dados, metodologias, instrumentos...) acessíveis a sociedade. A produção, disseminação e avanço do conhecimento são possíveis com o processo colaborativo entre os pares e as mentes curiosas como parte da investigação intelectual, do funcionamento da atividade acadêmica e científica, mesmo antes de ela se ter sido cristalizada e institucionalizada nas suas formas atuais. A ciência normal, tal como definida por Thomas Khun, é cumulativa e baseada no acesso e utilização do conhecimento previamente construído. (Rodrigues, 2015)

A iniciativa de conteúdo aberto tem beneficiado pesquisadores acadêmicos, autores, professores e estudantes, assim aumentando a circulação democrática de conhecimento aberto. Concomitante, com as tecnologias de acesso aberto, a aprendizagem aberta foi incentivada com o rápido crescimento de recursos educacionais abertos, repositórios abertos e cursos online abertos. A noção de abertura não se limita apenas à comunidade científica, mas está direcionada a todas as comunidades, instituições e organizações que visam a criação de conhecimento através de processos, metodologias, tecnologias e conteúdos amplamente abertos e disseminados em diferentes formatos, tais como texto, imagem, som ou vídeo (Willinsky, 2006).

\section{RRI: ORIGEM E PROJETOS}

No fim do século XX, a União Europeia criou o chamado Grupo Europeu sobre Ética em Ciências e Novas Tecnologias - EGE - para promover maior conscientização dos aspectos éticos nas políticas de promoção tecnológica. O EGE foi uma iniciativa pioneira que permitiu tornar visível, na agenda da comunidade, a dimensão ética do desenvolvimento científico. Em 2001, a Comissão Europeia lançou o plano de ação "Ciência e Sociedade" com a intenção genérica de aproximar a comunidade científica com a sociedade aprendente (Assmann, 1999) e, assim, estabelecer algumas pontes de diálogo entre ambas as esferas. No mesmo ano de 2001, Larry Lessig fundou a licença aberta Creative Commons. Em 2002, 
o Massachusetts Institute of Technology - MIT iniciou a rede OpenCourseWare, e o termo Recursos Educacionais Abertos (REA) foi criado durante um evento organizado pela Unesco em 2002.

O plano de ação da Comissão Europeia transformou-se no programa de desenvolvimento científico e tecnologia denominado "Ciência na Sociedade", no inglês Science in Society - SiS, como parte do FP7. O objetivo central foi o de ampliar e aprofundar o diálogo entre a comunidade científica e a sociedade civil com várias ações através de engajamento público, fóruns de diálogo e objetivos compartilhados de modo bidirecional entre cientistas e cidadãos.

Desde 2010, um dos resultados de destaque do grupo SIS foi apresentação do termo "Pesquisa e Inovação Responsáveis" como um caminho para conciliar as aspirações dos cidadãos com as ambições dos agentes da pesquisa e inovação (Von Schomberg (2013). Ou seja, através do RRI os agentes e representantes sociais trabalham juntos durante todo o processo de pesquisa e inovação, a fim de melhor alinhar o processo e seus resultados com os valores, necessidades e expectativas da sociedade.

Segundo Sutcliffe (2011) e Stilgoe, Owen \& Macnaghten (2013), os debates atuais sobre RRI sugerem a inclusão de vários fatores em conformidade com os valores sociais, a fim de maximizar os benefícios e reduzir riscos e incertezas com o propósito de:

- maior alcance de um benefício social ou ambiental;

- envolvimento coerente e contínuo da sociedade, do começo ao fim do processo;

- inclusão de grupos públicos e não governamentais, que estão conscientes do bem público;

- antecipação os impactos sociais, éticos e ambientais, riscos e oportunidades;

- gestão dos problemas e oportunidades com adaptação e resposta rápida às mudanças;

- abertura e a transparência no processo de pesquisa e inovação.

No ano de 2014, no programa Horizon 2020, destacou-se mais fortemente o programa "Ciência com e para a sociedade" (SwafS) como sucessor do programa SIS sinalizando uma mudança de orientação para um maior ligação e envolvimento da sociedade com a investigação. O objetivo do SwafS é desenvolver formas inovadoras de conectar a ciência com a sociedade para que a população possa superar os desafios sociais, tais como desenvolver habilidades de investigação para acompanhar, compreender e apropriar-se das inovações científicas, buscar e produzir conhecimento, discernir fontes confiáveis das falsas e tomar decisões com base em evidências. Torna-se um grande desafio nesta década propiciar a ciência mais atrativa (nomeadamente para os jovens), aumentar o interesse da 
sociedade pela inovação e abrir novas atividades de pesquisa e inovação, conforme destacado pela Comissão Europeia.

"Há momentos em que a ciência parece perder a conexão com a sociedade e suas necessidades, e às vezes seus objetivos não são totalmente compreendidos, mesmo que sejam bem-intencionados. A falta de uma linguagem comum e o rápido progresso em muitas áreas de pesquisa aumentaram a preocupação do público ou contribuíram para a ambivalência sobre o papel que a ciência e a tecnologia desempenham na vida cotidiana. Mas a ciência não pode trabalhar isoladamente, e os avanços na ciência e na tecnologia não são um objetivo por direito próprio.” (Comissão Europeia, 2013)

O programa "Ciência com e para a sociedade" é fundamental para abordar os desafios do mundo global incluindo da sociedade Europeia apresentados pelo Horizon 2020, criando capacidades e desenvolvendo formas inovadoras de conectar a ciência bem próxima da sociedade. Isso torna a ciência mais atrativa (nomeadamente para os jovens), aumenta o interesse da sociedade com a inovação e abre novas atividades de pesquisa e inovação.

O RRI visa a criação de uma política de Pesquisa e Inovação, orientada pelas necessidades da sociedade e envolvendo todos os atores sociais (pesquisadores, cidadãos, decisores políticos, empresas, organizações do terceiro setor, etc.) através de abordagens participativas e inclusivas.

“A pesquisa e a inovação responsáveis” é uma abordagem que antecipa e avalia possíveis implicações e expectativas sociais em relação à pesquisa e inovação, com o objetivo de promover o planejamento de uma pesquisa e inovação inclusiva e sustentável (Comissão Europeia Horizon2020, 2014)

No decorrer desse programa, o termo Pesquisa e Inovação Responsáveis foi publicado em várias referências, e também vários projetos foram financiados sobre essa abordagem. O primeiro edital na área de educação para ampliar a conscientização do conceito de RRI através da aprendizagem baseada em Pesquisa foi lançado em 2013 no último ano do programa FP7 SIS. Deste modo, foram financiados 5 projetos implementados no período de 2014 a 2017. Na área de Ensino Secundário surgiram quatro projetos: ENGAGE, Irresistible, PaRRIse, Ark of Inquiry. E o quinto projeto financiado foi na área mais ampla de pesquisa Europeia (ERA - European Research Area) para promover o conhecimento e a adoção de práticas de ciência aberta: FOSTER.

Para apoiar a comunidade científica com RRI foram financiados diversos projetos dentre eles: RRI tools, Great, Progress, resAgora and Responsibility.

Em seguida, no programa Horizon 2020 foram contemplados mais outros projetos sendo implementados no período de 2015 a 2020. No ensino superior 
surgiram: HEIRRI e ENRRICH, na área de Ensino Secundário: Perform e Open Schools for Open Societies; e na área científica: FOSTERPlus, FIT4RRI e New HORRIZON.

Algumas publicações-chave da Comissão Europeia:

- Science Education for Citizenship;

- Lab Fab App: investindo no futuro desejável.

Os editais de novos projetos de pesquisa incentivam iniciativas que buscam objetivos claros de acordo com o programa e que permitem avanço do RRI. Para isso, torna-se necessário desenvolver critérios quantitativos e / ou indicadores qualitativos para avaliar o impacto social e ético da pesquisa, além disso, integrar os próprios princípios de RRI na avaliação do projeto para o programa Horizon 2020.

O projeto FOSTER desenvolveu uma taxonomia de Ciência Aberta para, por um lado, descrever e mapear o amplo campo conceptual da ciência aberta e, por outro lado, facilitar a categorização dos recursos de educação e treinamento que o projeto recolhe no seu Portal.

\section{Open Science Taxonomy}

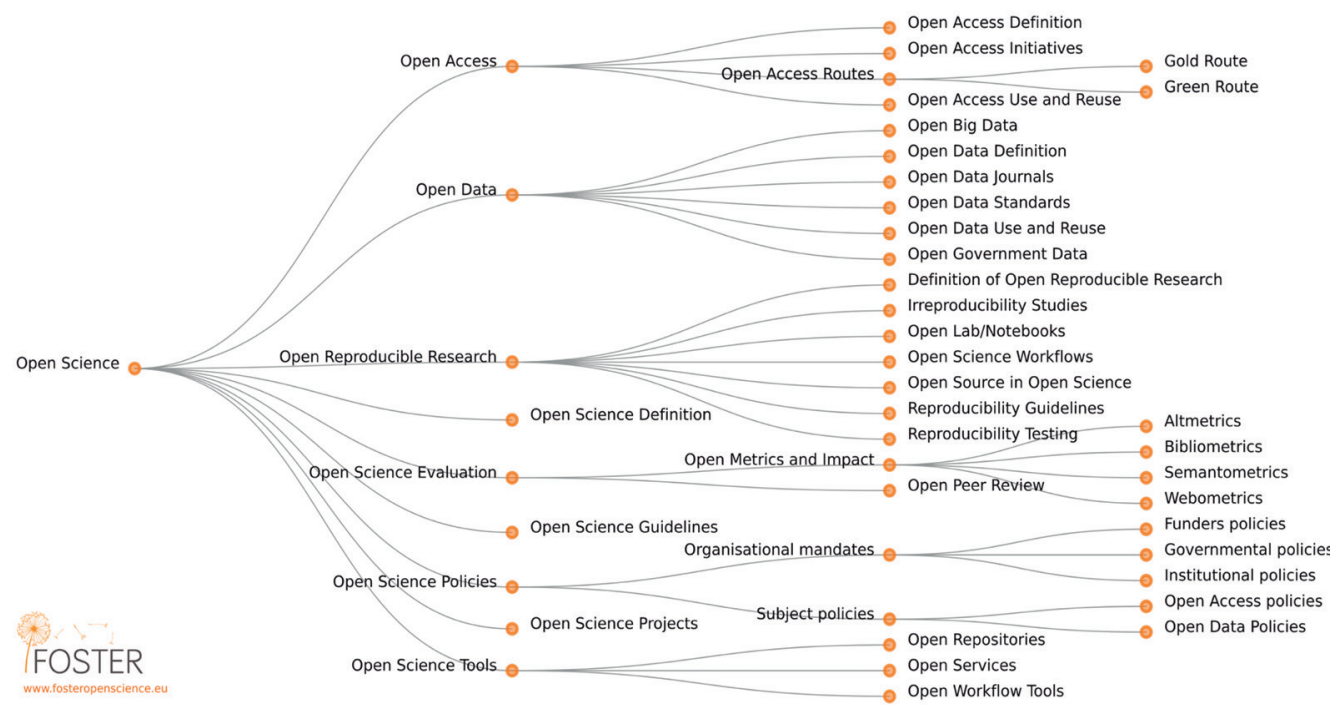

Figura 1 A taxonomia de ciência aberta do projeto FOSTER, contendo 9 conceitos de primeiro nível, e algumas dezenas de conceitos de segundo e terceiro níveis.

Para além da taxonomia de ciência aberta, o FOSTER também vem a acolher taxonomias de outras áreas relacionadas e desenvolvidas no contexto de outros projetos, com a participação da Universidade do Minho e/ou da Open University, como a taxonomia de Text and Data Mining (Figura 2) do projeto OpenMinted 
$<$ http://openminted.eu/> e a taxonomia de Responsible Research and Innovation (Figura 3) do projeto FIT4RRI <https://fit4rri.eu/>.

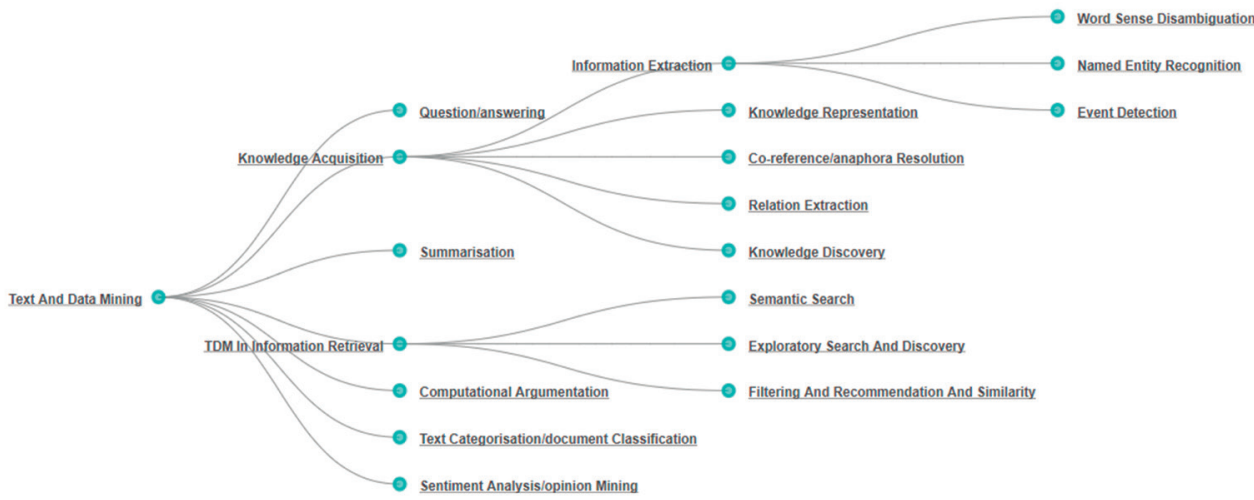

Figura 2 Taxonomia de mineração de texto e dados do projeto OpenMinted.

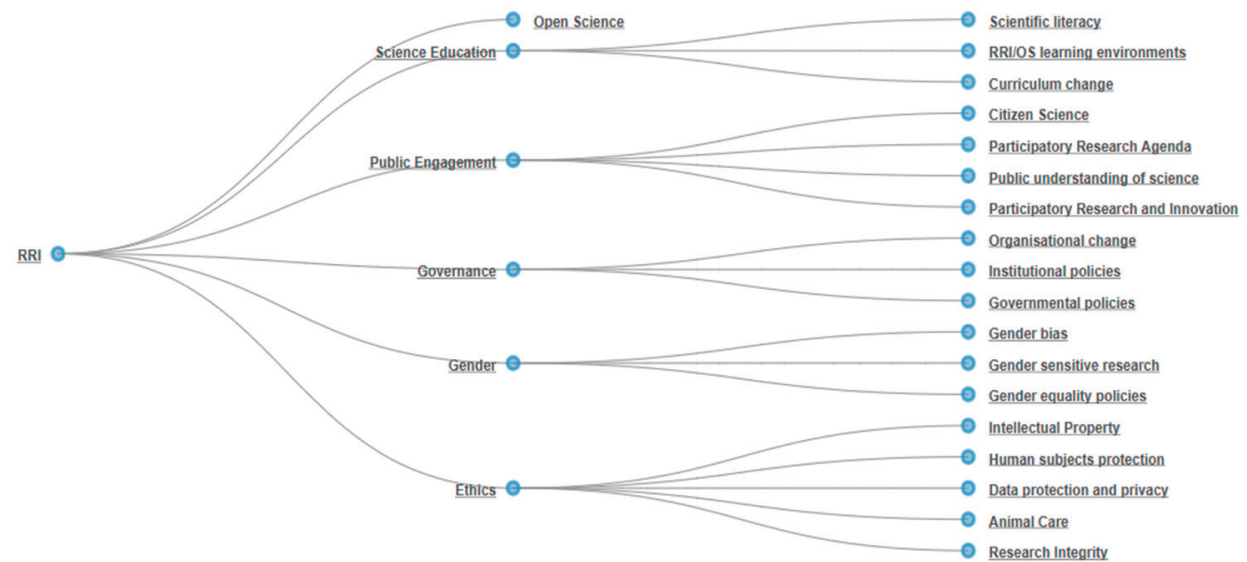

Figura 3 Taxonomia de pesquisa e inovação responsáveis do projeto FIT4RRI.

O projeto europeu ENGAGE desenvolveu um modelo de habilidades-chave de investigação para Pesquisa e Inovação Responsáveis com base em quatro dimensões com o propósito de preparar estudantes para cidadania responsável e carreira profissional para futuro sustentável (OKADA et al., 2016a):

1. Impacto tecnológico: o desenvolvimento tecnológico é a base para um futuro melhor, mas para isto, deve ser planejado cuidadosamente para maximizar os benefícios e reduzir riscos. 
2. Ciência emergente: a ciência não é um processo individual, mas sim um empreendimento complexo e colaborativo realizado em parcerias. O desenvolvimento da ciência ocorre através de financiamentos oferecidos por grandes corporações e politicamente determinados. Para um mundo sustentável e próspero, a pesquisa científica deve estar alinhada com as necessidades da sociedade de acordo com seus valores sociais, ambientais e econômicos.

3. Pensamento de valores: a tecnologia e ciência emergentes exigem um pensamento sócio ético científico para lidar com questões e resultados incertos e não esperados. O processo de tomada de decisão deve ocorrer de acordo com os valores, visão e opiniões informadas de todos os distintos membros da sociedade

4. Ciência na mídia: grande parte da informação científica é interpretada pela mídia que por sua vez oferece visão desequilibrada, tendenciosa e sensacionalista. As fontes de informações precisam ser avaliadas em termos de sua finalidade, confiabilidade científica, atualização e ocorrência.

Com base nestas quatro dimensões foram estabelecidas dez habilidades para investigação visando a Pesquisa e Inovação Responsáveis (Okada, 2016a):

1. Elaborar perguntas: definir questões científicas com clareza para investigar fatores, causa ou correlações.

2. Interrogar fontes: questionar diferentes fontes pesquisadas e avaliar sua validade e veracidade.

3. Analisar consequências: avaliar o mérito de uma solução perante os problemas do mundo real, refletindo sobre as implicações econômicas, sociais e ambientais.

4. Estimar riscos: medir os riscos e benefícios avaliando o impacto para a sociedade.

5. Analisar dados: interpretar dados de diversos formatos e com variedade de metodologias para identificar padrões e tendências e assim fazer inferências e extrair conclusões.

6. Tirar conclusões: determinar se afirmações na pesquisa são suportadas suficientemente por dados.

7. Criticar afirmações: examinar a consistência e coerência da evidência, ou seja, qualidade, precisão e suficiência para apoiar ou refutar as afirmações.

8. Justificar opiniões: sintetizar o conhecimento científico, implicações e valores de perspectivas para formar uma opinião suportada por evidência e raciocínio científico indicando valores apoiados no pensamento. 
12. Usar ética: compreender questões relacionadas com juízo de valor utilizando métodos para apoiar o pensamento ético para tomada de decisão, por exemplo, utilitarismo, direitos e deveres e virtudes.

13. Comunicar ideias: apresentar ideias claras seja através da narrativa escrita, verbal, midiática visual e oral com diversos formatos utilizando características ou padrões científicos.

A Figura 4 descreve as 10 habilidades de investigação científica para o RRI, nas quais os estudantes são envolvidos a desenvolverem competências por meio de projetos na área das ciências contemporâneas (Okada, 2016b).

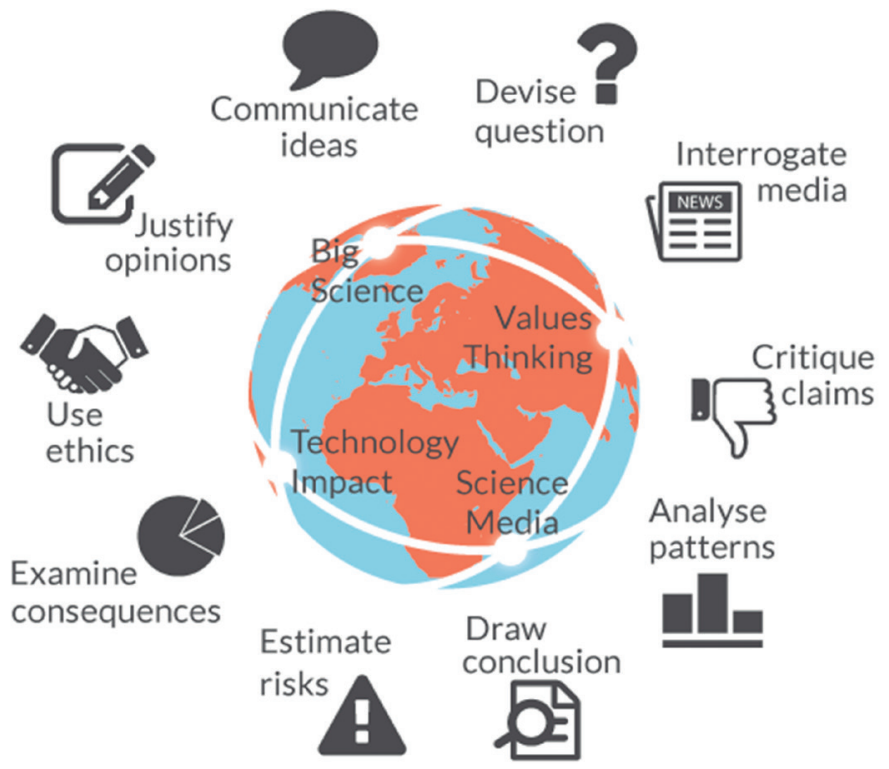

Figura 4 Habilidades-chave de investigação para RRI.

\section{REFLEXÕES SOBRE RRI E OPEN SCHOOLING}

A educação aberta com ciência aberta e escolarização aberta são essenciais para preparar indivíduos e comunidades para a participação crítico-colaborativa com conhecimento, habilidades e atitudes. Ou seja, para viabilizar a RRI, todos os representantes da sociedade precisam estar aptos a identificar as necessidades prioritárias da sociedade, compreender os avanços científicos e interagir com visão, pensamento e ação sócio ético científica (Raticliffe, 2003).

A abordagem RRI requer a discussão reflexiva das intenções metodologias, implementação, análise e resultados dos avanços científicos para que o processo seus resultados do desenvolvimento científico tecnológico possa ser alinhado com os valores, necessidades e expectativas da sociedade. Neste processo, os educado- 
res e formadores de educadores ocupam papel central na formação dos estudantes, cidadãos e profissionais de modo global para que possam se envolver, participar e contribuir efetivamente para RRI em todas as etapas:

- No estágio inicial: para obter conhecimento relevante relacionado à pesquisa e assim poder participar da elaboração de agendas e editais incluindo programas e políticas de financiamento a pesquisa.

- No decorrer do processo: para estar ciente e obter informação com base em evidência atualizada, confiável e imparcial e assim poder expressar opinião em relação às possibilidades de resultados e potenciais consequências da inovação com opções abertas.

- Na finalização: para estar ciente dos resultados e assim poder avaliar efetivamente o impacto em termos de necessidades sociais atendidas ou não, incluindo perspectivas de valores considerados no processo.

- A abordagem RRI tem reunido diversos atores nos projetos financiados pela Comissão Europeia incluindo cidadãos, pesquisadores, instituições e governos. Estes atores sociais têm interagido através de metodologias inclusivas e participativas em todas as etapas dos processos de pesquisa e inovação e em todos os níveis de governança desde a definição da agenda até a concepção, implementação e avaliação.

Os projetos de RRI destacam cinco grupos da sociedade:

1. Criadores e gestores de políticas: incluem desde formadores de opinião que influenciam políticas até os próprios agentes de políticas, diretores de centros de pesquisa e representantes de sociedades científicas, seja a nível europeu, nacional ou local. Todos aqueles que definem como a pesquisa e a inovação devem ser realizadas em sua área de influência pertencem a este grupo.

2. Comunidade de pesquisa: são os acadêmicos pesquisadores, cientistas inovadores, gerentes de pesquisa, oficiais de assuntos públicos e de comunicação. Todas as pessoas que apoiam os diversos aspectos do sistema de Pesquisa e Inovação pertencem a este grupo.

3. Comunidade de educação: referem-se aos professores, formadores de docentes, coordenadores pedagógicos, desenvolvedores de cursos, estudantes, profissionais de museus de ciências e famílias. Todos os que estão envolvidos com educação em todos os níveis, desde escolas primárias até estudos de pós-graduação, pertencem a este grupo.

4. Indústria empresarial: trata-se dos grupos de empreendedores profissionais de grande, média e micro empresa, incluindo organizações e instituições transnacionais. Todos os que estão envolvidos em negócios cuja a base é pesquisa e a inovação fazem parte desta categoria. 
5. Sociedade e organização civil: são os indivíduos às organizações, incluindo ONGs, comunidades, profissionais dos meios de comunicação, representantes da sociedade civil. Todos os cidadãos ocupam papel essencial para direcionar a pesquisa e a inovação para atender as necessidades da sociedade.

Uma das recomendações-chave da Comissão Europeia é conectar a aprendizagem formal, informal e não formal através da escolarização aberta para ampliar o interesse dos jovens por ciência e RRI, ampliando o número de profissionais e cidadãos inovadores e responsáveis.

- Aprendizagem formal: a aprendizagem ocorre de forma organizada em ambiente estruturado (por exemplo, em uma instituição de educação, treinamento e/ou no trabalho) com intenções explícitas de aprendizagem (em termos de objetivos, tempo ou recursos). A aprendizagem formal é intencional do ponto de vista do estudante. Tipicamente leva à validação e certificação.

- Aprendizagem não formal: aprendizagem que está incorporada em atividades planejadas não sempre designadas de forma explícita como aprendizagem formal (em termos de objetivos de aprendizagem, tempo de aprendizagem ou apoio à aprendizagem), mas que contém um dos elementos de aprendizado. A aprendizagem não-formal é intencional do ponto de vista do estudante, que pode acontecer em museus, campos/clubes de ciência etc.

- Aprendizagem informal: aprendizagem resultante de atividades diárias relacionadas ao trabalho, família ou lazer. Não é organizada ou estruturada em termos de objetivos, tempo ou suporte de aprendizagem. A aprendizagem informal é principalmente não intencional da perspectiva do estudante.

- Escolarização aberta (open schooling) referem-se às parcerias entre escolas, comunidades locais, famílias e instituições visando conectar as três abordagens de aprendizagem (formal, informal e não formal).

A aprendizagem informal desempenha um papel fundamental na formação do desenvolvimento do pensamento científico e da literacia científica (AAAS, 1993), pois emerge a partir do que os sujeitos estão interessados em contextos reais no mundo e permite que eles possam explorar e derivar seu próprio entendimento. $\mathrm{Na}$ aprendizagem formal, ou seja, no modo tradicional de ensino, esta ordem está invertida, o conhecimento vem primeiro e as aplicações interessantes do mundo real só seguem mais tarde. A aprendizagem não formal está entre estes dois cenários, o conhecimento e o contexto real estão interligados, porém de modo menos frequente.

O conceito de escolarização aberta emergiu muito recentemente como uma das recomendações da Comissão Europeia para promover a educação científica para a cidadania responsável através de parcerias entre todos os atores visando melhor conexão entre aprendizagem formal, informal e não formal para que os 
estudantes possam ampliar conhecimentos, habilidades e atitudes dentro e fora da escola. (Ryan, 2015)

$\mathrm{Na}$ escolarização aberta, as escolas em cooperação com outras partes interessadas tornam-se um agente do bem-estar comunitário conectando os estudantes com suas famílias que são parceiras na vida e nas atividades escolares e com os profissionais de empresas e sociedade civil que trazem projetos da vida real para a sala de aula. Os gestores políticos têm o papel de integrar as boas práticas e insights dos projetos nas políticas públicas, portanto, garantindo sustentabilidade e impacto além do tempo do financiamento dos projetos (Comissão Europeia, 2018).

O próximo passo no fim do programa Europeu Horizon 2020 é iniciar projetos de escolarização aberta para promover a pesquisa e inovação responsáveis através de número maior de parceria entre os estudantes, professores, família, profissionais da área científica e tecnológica, incluindo também gestores políticos.

"Espera-se que, a curto prazo que o desenvolvimento de parcerias entre escolas, comunidades locais, organizações da sociedade civil, universidades e indústria possa contribuir para uma sociedade com estudantes mais interessados cientificamente e com uma maior conscientização de carreiras científicas. A médio prazo, as atividades de escolarização aberta devem proporcionar aos cidadãos e aos futuros pesquisadores as ferramentas e habilidades para tomar decisões e escolhas informadas e, a longo prazo, essa ação deve contribuir para os objetivos de aumentar o número de cientistas e pesquisadores na Europa”. (Comissão Europeia 2018).

\section{CONCLUSÕES}

O objetivo deste texto foi introduzir o conceito de RRI e iniciar o debate sobre a Educação Aberta com Ciência Aberta e Escolarização Aberta para a Pesquisa e Inovação Responsáveis na formação de educadores e profissionais do futuro.

\section{Alguns fatos foram destacados:}

- A circulação e co-construção do conhecimento tornaram-se muito mais abrangentes e rápidas com a revolução digital.

- A ciência aberta ampliou-se muito mais transformando-se num movimento para tornar a pesquisa científica tanto os resultados como processo (dados, metodologias, instrumentos...) mais acessíveis à sociedade.

- A produção, disseminação e avanço do conhecimento são possíveis com o processo colaborativo entre os parceiros.

- A iniciativa de conteúdo aberto tem beneficiado pesquisadores acadêmicos, autores, professores e estudantes, assim aumentando a circulação democrática do conhecimento aberto.

- "Ciência com e para a sociedade" é fundamental para abordar os desafios do mundo global. 
- A “pesquisa e a inovação responsáveis” é uma abordagem que antecipa e avalia possíveis implicações e expectativas societais em relação à pesquisa e inovação.

- O modelo de habilidades-chave de investigação para Pesquisa e Inovação Responsáveis visa preparar estudantes para cidadania responsável e carreira profissional para futuro sustentável.

- Os educadores e formadores de educadores ocupam papel central na formação dos estudantes, cidadãos e profissionais de modo global para que todos possam se envolver, participar e contribuir efetivamente com a RRI.

Para continuar o debate finalizamos com algumas questões:

- Quais as metodologias, os princípios e os artefatos existentes que possam ser usados para auxiliar os professores na formação dos estudantes com Ciência Aberta e Escolarização Aberta para a RRI?

- Como ampliar o interesse dos jovens para identificar as necessidades prioritárias da sociedade, compreender os avanços científicos e interagir com visão, pensamento e ação sócio ético científicas?

- Como as parcerias podem ser estabelecidas entre a comunidade de educação, a comunidade de pesquisa, a indústria empresarial, a sociedade e organização civil e os criadores e gestores de políticas?

\section{AGRADECIMENTOS}

Este texto é o início do próximo projeto sobre escolarização aberta com instituições europeias e brasileiras. Participe deste processo com suas ideias < aleokada.com>. Agradecemos todos os participantes da Rede Colearn, os revisores deste artigo e os organizadores dessa obra.

\section{REFERÊNCIAS}

American Association for the Advancement of Science (AAAS). (1993). Benchmarks for Science Literacy. Oxford University Press.

Assmann E. H. (1999) Reencantar a educação: rumo à sociedade aprendente. Petrópolis: Vozes.

Castells, M. \& Cardoso, G. (Orgs.). 2005. A Sociedade em Rede: do conhecimento à ação política; Conferência. Belém (Por): Imprensa Nacional. Livro organizado a partir de Conferência promovida pelo então Presidente da República de Portugal, Jorge Sampaio, em 4 e 5 de Março de 2005, no Centro Cultural de Belém.

Comissão Europeia. (2012). Responsible Research and Innovation: Europe's ability to respond to societal challenges. Accessed: 2015 april 9. <http://ec.europa.eu/research/science-society/document_library/pdf_06/responsibleresearch-and-innovation-leaflet_en.pdf>. 
Comissão Europeia. (2013). “Options for Strengthening Responsible Research and Innovation - Report of the Expert Group on the State of Art in Europe on Responsible Research and Innovation” (PDF). doi:10.2777/46253. Retrieved 24 june 2014.

Comissão Europeia. (2014). Compreender as políticas da União Europeia: Investigação e inovação. Disponível em: <https://europa.eu/european-union/file/1487/download_pt?token=Earr8nyE $>$.

Comissão Europeia. (2013). Options for strengthening Responsible Research and Innovation. Brussels: European Commission. doi:10.2777/46253 https://ec.europa.eu/research/swafs/index.cfm?pg=about.

Comissão Europeia. (2014). What is Horizon 2020? Disponível em: <https://ec.europa. eu/programmes/horizon2020/en/what-horizon-2020>.

David, P. A. (2007). The Historical Origins of “Open Science”. Stanford Institute for Economic Policy Research, Stanford University. Disponível em: <http://siepr.stanford. edu/sites/default/files/publications/06-38_0.pdf>.. (9. 11. 2016).

Okada, A. (2016a). Engaging Science: Innovative Teaching for Responsible Citizenship. Milton Keynes: The Open University - UK, 2016.

Okada, A. (2016b). Responsible research and innovation in science education report. Milton Keynes: The Open University - UK, 2016.

Okada, A. (2014). Competências Chave para Coaprendizagem na Era Digital: fundamentos, métodos e aplicações. Santo Tirso - Portugal: WHITEBOOKS.

Osset Hernández, M. (2014). Responsible Research and Innovation (RRI): the next frontier in R+ D. Revista Lasallista de Investigación, 11(1), 51-55.

Owen, R., Macnaghten, P., and Stilgoe, J. (2012). Responsible research and innovation: From science in society to science for society, with society. Science and Public Policy, 39(6), 751-760.

Pamlin, D. \& Armstrong S. (2015). Global Challenges 12 risks that threaten human civilisation. Global Challenges Foundation.

Ratcliffem.; Gracem. Science education for citizenship: teaching socio-scientific issues. Maidenhead: Open University Press, 2003.

Rodrigues, Eloy (2015). O acesso aberto e o futuro da investigação e comunicação científica. In: Bernardes, José Augusto Cardoso; Miguéis, Ana Maria Eva; Ferreira, Carla Alexandra S., (Coord.). A biblioteca da universidade. Permanência e metamorfoses. Coimbra: Imprensa da Universidade de Coimbra, 2015, ISBN: 978-989-26-1044-3. p. 207-228. Stilgoe, J., Owen, R., \& Macnaghten, P. (2013). Developing a Framework for Responsible Innovation. Research Policy, 42(9), 1568-1580.

Sutcliffe, H. (2011). A report on Responsible Research \& Innovation Director, https:// ec.europa.eu/research/science-society/document_library/pdf_06/rri-report-hilary-sutcliffe_en.pdf Retrieved 24 june 2014.

Von Schomberg, R. (2013). “A vision of responsible research and innovation”. In: R. Owen, J. Bessant, M. Heintz (Eds.). Responsible innovation: managing the responsible emergence of science and innovation in society. Wiley, London (2013).

Willinsky, J. (2006). The access principle: the case for open access to research and scholarship. Cambridge, Mass.: MIT Press. 